\title{
Cardiovascular Effects of Intravenous Oxytocin in Elective Caesarean Section - A Study from Alappuzha, Kerala
}

\author{
Biby Mary Kuriakose ${ }^{1}$, Veena Nadarajan² \\ 1, 2 Department of Anaesthesiology, Government T. D. Medical College, Alappuzha, Kerala, India.
}

\section{ABSTRACT}

\section{BACKGROUND}

Oxytocin is a peptide hormone produced in the hypothalamus, stored, and released by the posterior pituitary. Oxytocin is commonly administered during caesarean section to minimise blood loss. It can cause hypotension, tachycardia, arrhythmias, and decrease in cardiac output and ST-T wave changes which may be deleterious in hypovolemic and high-risk cardiac patients. Cardiovascular effects of oxytocin have not been well investigated. The purpose of this study was to determine the cardiovascular effects of oxytocin (5U) administered as rapid intravenous infusion over 1 minute followed by a maintenance infusion of $10 \mathrm{U}$, study other adverse effects of oxytocin, assess uterine tone and the need for additional uterotonics and also assess the blood loss. We also wanted to maintain adequate uterine contractility to minimise blood loss and prevent post partum haemorrhage and also know if the cardiovascular effects of oxytocin could be tolerated by normal parturients.

\section{METHODS}

This is a prospective study. Hundred parturients undergoing elective caesarean delivery, under spinal anaesthesia were given $5 \mathrm{U}$ of oxytocin as rapid intravenous infusion over 1 minute followed by a $10 \mathrm{U}$ maintenance intravenous infusion. Intraoperative heart rate, non-invasive blood pressure (NIBP) and continuous electrocardiograph (ECG) changes were noted. Patients were observed for other adverse effects like chest pain, dysrhythmias, nausea, vomiting and generalised flushing. Uterine tone and the need for additional uterotonics were assessed.

\section{RESULTS}

Tachycardia was observed for the initial 2 minutes after oxytocin bolus which returned to the baseline values within 15 minutes. Diastolic blood pressure (12.7 $\%)$ and mean arterial pressure (9.6\%) showed greater fall than systolic blood pressure (5.9\%) due to the effects of oxytocin. Among the 100 parturients, one parturient complained of chest pain which developed during oxytocin bolus and subsided after 2 minutes, one had ST depression and another one developed atrial arrhythmias.

\section{CONCLUSIONS}

It can be inferred that oxytocin in the dose studied is safe in parturients who are normovolemic and without cardiac risk factors. It is effective in achieving adequate uterine tone and reducing blood loss.

\section{KEY WORDS}

Oxytocin, Cardiovascular Effects, Caesarean Section, Uterine Tone
Corresponding Author:

Dr. Veena Nadarajan, Kovilakam House, Pazhaveedu P.O., Alappuzha - 688009, Kerala, India. E-mail:drveenadutt@gmail.com

DOI: $10.14260 /$ jemds/2021/773

How to Cite This Article:

Kuriakose BM, Nadarajan V. Cardiovascular effects of intravenous oxytocin in elective caesarean section - a study from Alappuzha, Kerala. J Evolution Med Dent Sci 2021;10(45):3821-3826, DOI: $10.14260 /$ jemds/2021/773

Submission 09-11-2021,

Peer Review 15-11-2021,

Acceptance 08-12-2021,

Published 11-12-2021.

Copyright (C) 2021 Biby Mary Kuriakose et al. This is an open access article distributed under Creative Commons Attribution License [Attribution 4.0 International (CC $B Y 4.0)]$ 


\section{BACKGROUND}

Oxytocin is a nine amino acid polypeptide synthesised in the hypothalamus and transported down the axons to the posterior pituitary for secretion into blood. Sir Henry H Dale first identified oxytocin and its uterine contractile properties in 1906. Oxytocin was first synthesised by a biochemist Vincent Du Vigneau in 1953 who was later recognized with Nobel prize.

Oxytocin is the most commonly used uterotonic agent in obstetrics. It is routinely administered after both normal and operative delivery to initiate and maintain adequate uterine contractility for minimizing blood loss and preventing postpartum hemorrhage. ${ }^{1}$

Several regimens of oxytocin have been tested during caesarean delivery with variable wanted (uterotonic) and unwanted (cardiovascular) effects. ${ }^{2-8}$

Oxytocin is rapidly metabolized by hepatic oxytocinases and cleared in the urine and bile, resulting in a half-life of less than 6 minutes. ${ }^{9}$

Consequently, oxytocin is commonly given as an intravenous (IV) bolus followed by IV infusion for adequate uterine contraction. Larger doses of oxytocin injected rapidly is known to produce various adverse effects such as hypotension, tachycardia, nausea, vomiting, chest pain, headache, flushing, myocardial ischemia, ST-T wave changes, pulmonary oedema, severe water intoxication and convulsions. ${ }^{10}$

The use of high bolus doses (e.g., 10 IU of oxytocin) can cause deleterious cardiovascular changes in the patient, especially in situations of hypovolemia or low cardiac reserve. ${ }^{11}$

Furthermore, high doses of oxytocin for prolonged periods may lead to desensitization of oxytocin receptors in myometrium, resulting in clinical inefficiency.

Hemodynamic effects of 3 IU of oxytocin bolus vs. infusion was studied by Susmita Bhattacharya et al. Thomas et al. compared the hemodynamic effects of $5 \mathrm{IU}$ of oxytocin given as bolus and infusion.

We studied the cardiovascular effects, other adverse effects and uterine contraction due to oxytocin $5 \mathrm{U}$ rapid intravenous infusion followed by $10 \mathrm{U}$ maintenance infusion.

\section{Aims and objectives \\ Primary Objective \\ To study the cardiovascular effects of 5 units of oxytocin administered as rapid intravenous infusion over 1 minute followed by a $10 \mathrm{U}$ maintenance infusion in $500 \mathrm{ml}$ normal saline over 1 hour for elective caesarean section at Govt. T.D. Medical College Hospital, Alappuzha, Kerala.}

\section{Secondary Objectives}

- To assess the uterine tone and to evaluate the need for other uterotonics.

- To study other adverse effects of oxytocin.

To quantify the blood loss.

\section{METHODS}

This prospective study was conducted from September 2020 to February 2021 at Govt. T.D. Medical College Hospital, Alappuzha, Kerala. After obtaining clearance from Institutional Research and Ethics committees. Hundred and eight parturients of American Society of Anaesthesiologists (ASA) physical status 2, aged between 21 and 35 years, scheduled for elective caesarean section under spinal anaesthesia were recruited.

Sample size was calculated using the formula $\frac{Z \alpha^{2} * S D^{2}}{d^{2}}$

$\mathrm{Z} \alpha=1.96$ (95\% Confidence level)

$\mathrm{SD}=$ Standard deviation. Based on a study conducted by Thomas et al. ${ }^{7}$

Standard deviation was taken as 10

$\mathrm{d}=$ absolute precision, 2

Sample size $=\frac{1.96 * 1.96 * 10^{2}}{4}=96$

Patients with active labour pain, ruptured membranes, multiple gestation, cardiovascular instability, preeclampsia and eclampsia, diabetes mellitus, placenta previa and height less than $150 \mathrm{~cm}$ were excluded from this study. 8 parturients who developed excessive hypotension after spinal anaesthesia were excluded from the study.

A detailed pre-anaesthetic check-up was done. A written informed consent was obtained from these parturients. Parturients were instructed to avoid solid food for 6 hours and were allowed to drink plain water up to 2 hours before the surgery. They were given T. omeprazole $20 \mathrm{mg}$ and $\mathrm{T}$. metoclopramide $10 \mathrm{mg}$ at $10 \mathrm{pm}$ on day before surgery and 6 am on the day of surgery.

When the patients reached operating room, intravenous line was established using an 18G cannula. Intravenous fluid ringer lactate was started. Co loading was done with ringer lactate. Patient monitors such as continuous 5 lead ECG with ST-T segment analysis, pulse oximeter, non-invasive automated blood pressure were attached. Baseline systolic blood pressure (SBP), diastolic blood pressure (DBP), mean arterial pressure (MAP) and heart rate (HR) were recorded before administering spinal anaesthesia.

Spinal anaesthesia was given with $1.6 \mathrm{ml}$ hyperbaric bupivacaine $0.5 \%$ with 60 microgram of buprenorphine at L3-L4 space with parturients in right lateral position using $25 \mathrm{G}$ spinal needle.

Parturients were then made supine with left lateral uterine displacement using appropriate wedge. Surgery was started after achieving T6 sensory level.

The SBP, DBP, MAP and HR were recorded before giving inj oxytocin. After delivery of baby, inj oxytocin 5 units was given as a rapid iv infusion over 1 minute followed by 10 units oxytocin in $500 \mathrm{ml}$ normal saline over $1 \mathrm{hr}$. Uterine tone was assessed by obstetrician every 3 minutes and designated as 'adequate 'or 'inadequate.'

Intra-operative HR, BP and ECG changes were monitored. $\mathrm{HR}$, systolic BP, diastolic BP and MAP were measured at 2 minute intervals for up to 6 minutes \& then 5 minute intervals up to 30 minutes \& 10 minute intervals for up to 1 hour. 
Other adverse effects like chest pain, nausea, vomiting and generalised flushing were noted. Parturients having a fall in MAP more than $20 \%$ were treated with ephedrine $6 \mathrm{mg}$ iv.

Parturients having inadequate uterine tone were treated with methylergometrine $0.2 \mathrm{mg}$ intramuscularly. The average blood loss was estimated from the number of mops used, the amount of blood in the suction bottle and from the surgical field.

\section{Statistical Analysis}

Categorical and quantitative variables were expressed as frequency (percentage) and mean $+\mathrm{SD}$ respectively. Repeated measure analysis of variance (ANOVA) was carried out to test the variation of quantitative parameters at different time interval. For all statistical interpretations, $\mathrm{p}<$ 0.05 was considered the threshold for statistical significance. Statistical analyses was performed by using a statistical software package SPSS (statistical package for social sciences), version 20.0 .

\section{RESULTS}

The study was conducted from September 2020 to February 2021. Hundred and eight parturients were enrolled in the study. Eight of them developed significant hypotension after spinal anaesthesia and were excluded from the study.

\begin{tabular}{|c|c|c|c|c|c|}
\hline Heart Rate & Mean & SD & $\mathbf{N}$ & F\# & $\bar{p}$ \\
\hline Baseline & 83.3 & 10.2 & 100 & \multirow{13}{*}{72.85} & \multirow{13}{*}{$P<0.01$} \\
\hline Before oxytocin & 84.1 & 11.2 & 100 & & \\
\hline $2 \min$ & 97.8 & 13.0 & 100 & & \\
\hline $4 \mathrm{~min}$ & 89.2 & 12.3 & 100 & & \\
\hline $6 \mathrm{~min}$ & 87.5 & 13.1 & 100 & & \\
\hline $10 \mathrm{~min}$ & 86.0 & 12.3 & 100 & & \\
\hline $15 \mathrm{~min}$ & 84.3 & 12.0 & 100 & & \\
\hline $20 \mathrm{~min}$ & 83.4 & 11.8 & 100 & & \\
\hline $25 \mathrm{~min}$ & 82.9 & 11.5 & 100 & & \\
\hline $30 \mathrm{~min}$ & 81.6 & 11.9 & 100 & & \\
\hline $40 \mathrm{~min}$ & 78.9 & 11.4 & 100 & & \\
\hline $50 \mathrm{~min}$ & 77.4 & 10.5 & 100 & & \\
\hline $60 \mathrm{~min}$ & 75.8 & 9.6 & 100 & & \\
\hline \multicolumn{6}{|c|}{ Table 1. Comparison of Heart Rate at Different Interval } \\
\hline
\end{tabular}

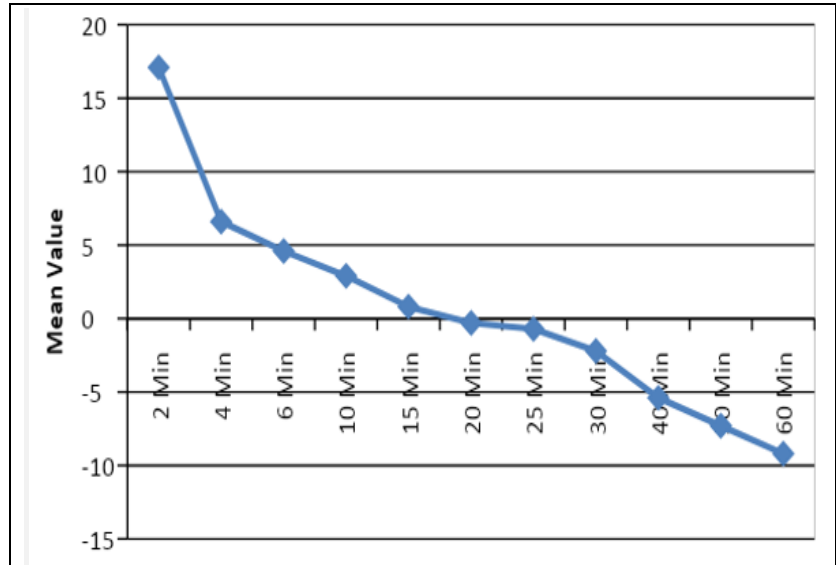

Figure 1. Regarding Percentage Increase of HR at Different Intervals of Time after Oxytocin

\begin{tabular}{|c|c|c|c|c|c|}
\hline SBP & Mean & SD & $\mathbf{N}$ & F\# & $\mathbf{p}$ \\
\hline Baseline & 122.4 & 8.5 & 100 & \multirow{13}{*}{52.49} & \multirow{13}{*}{$\mathrm{P}<0.0$} \\
\hline Before oxytocin & 114.5 & 8.6 & 100 & & \\
\hline $2 \min$ & 108.4 & 10.2 & 100 & & \\
\hline $4 \mathrm{~min}$ & 109.8 & 8.8 & 100 & & \\
\hline $6 \mathrm{~min}$ & 109.4 & 9.0 & 100 & & \\
\hline $10 \mathrm{~min}$ & 108.1 & 8.4 & 100 & & \\
\hline $15 \mathrm{~min}$ & 107.4 & 8.9 & 100 & & \\
\hline $20 \mathrm{~min}$ & 107.8 & 9.3 & 100 & & \\
\hline $25 \mathrm{~min}$ & 107.8 & 10.1 & 100 & & \\
\hline $30 \mathrm{~min}$ & 108.2 & 9.1 & 100 & & \\
\hline $40 \mathrm{~min}$ & 109.7 & 9.0 & 100 & & \\
\hline $50 \mathrm{~min}$ & 111.0 & 8.4 & 100 & & \\
\hline $60 \mathrm{~min}$ & 113.3 & 8.4 & 100 & & \\
\hline
\end{tabular}

$51 \%$ of parturients belong to the age group $26-30 \mathrm{yrs}$. $26 \%$ belonged to $21-25$ years and $23 \%$ belonged to $31-35$ years. The mean height of the parturients studied was 157.1 with SD 5 and weight was 66.3 with SD 10.5 .

The percentage increase in heart rate was maximum at 2 minutes after oxytocin rapid IV infusion, the mean value of which was $17.1 \%$.The heart rate values reached the baseline values after 15 minutes.

The decrease in systolic blood pressure was marked in the initial 30 minutes after oxytocin rapid IV infusion. The maximum fall observed was $5.9 \%$ at 15 minutes. Systolic blood pressure reached the baseline values nearly at 1 hour.

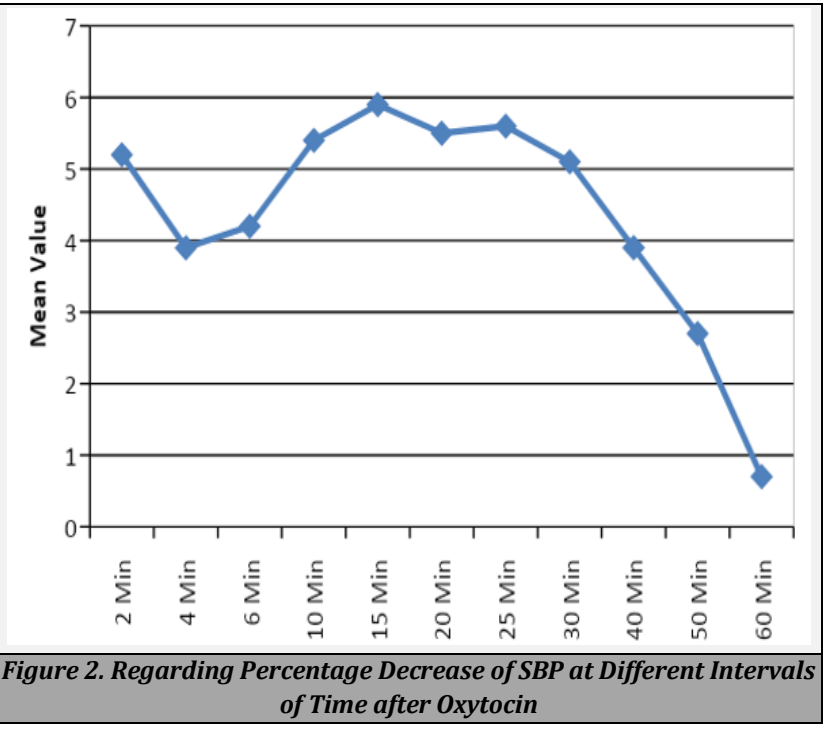

\begin{tabular}{|cccccc|}
\hline DBP & Mean & SD & N & F\# & p \\
Baseline & 74.5 & 6.7 & 100 & & \\
Before oxytocin & 65.5 & 8.0 & 100 & & \\
$2 \mathrm{~min}$ & 57.0 & 8.4 & 100 & & \\
$4 \mathrm{~min}$ & 59.1 & 7.9 & 100 & & \\
$6 \mathrm{~min}$ & 58.3 & 8.4 & 100 & & \\
$10 \mathrm{~min}$ & 57.1 & 8.0 & 100 & & \\
$15 \mathrm{~min}$ & 56.8 & 8.9 & 100 & 93.87 & \\
$20 \mathrm{~min}$ & 58.1 & 8.2 & 100 & & \\
$25 \mathrm{~min}$ & 57.9 & 9.1 & 100 & & \\
$30 \mathrm{~min}$ & 59.5 & 8.8 & 100 & & \\
$40 \mathrm{~min}$ & 62.7 & 7.6 & 100 & \\
$50 \mathrm{~min}$ & 64.4 & 8.3 & 100 & \\
$60 \mathrm{~min}$ & 66.3 & 8.2 & 100 & \\
\hline \multicolumn{7}{c}{ Table 3. Comparison of DBP at Different Interval } \\
\hline \multicolumn{7}{c}{} \\
\hline
\end{tabular}

Percentage decrease in diastolic blood pressure was maximum at 15 minutes after oxytocin rapid IV infusion, the mean value of which was $12.7 \%$. This was followed by a mean decrease of $12.5 \%$ at 2 minutes. Diastolic blood pressure reached the baseline values after 50 minutes. $\geq 20$ $\%$ reduction in diastolic blood pressure was observed in 30 parturients at 2 minutes and 15 minutes after oxytocin rapid infusion. 


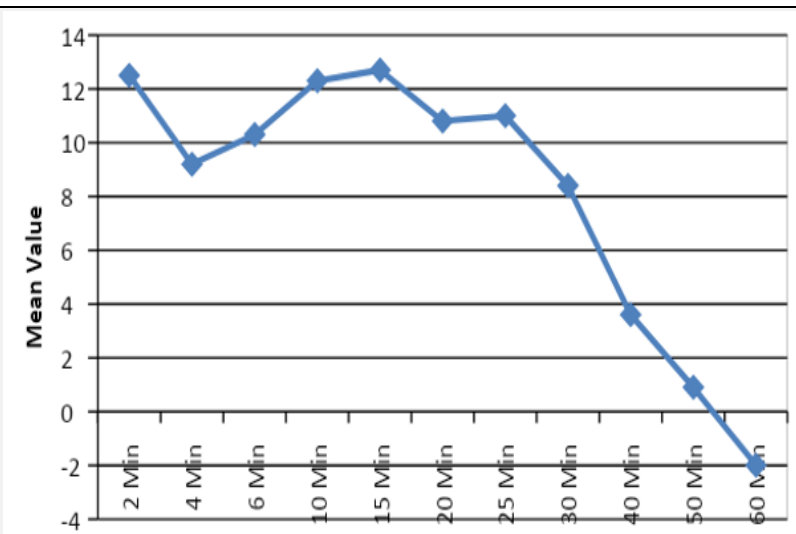

\begin{tabular}{|c|c|c|c|c|c|}
\hline \multicolumn{6}{|c|}{$\begin{array}{c}\text { Figure 3. Regarding Percentage Decrease of DBP at Different Interva } \\
\text { of Time after Oxytocin }\end{array}$} \\
\hline MAP & Mean & SD & $\mathbf{N}$ & F\# & $\bar{p}$ \\
\hline Baseline & 90.5 & 6.5 & 100 & \multirow{13}{*}{97.56} & \multirow{13}{*}{$\mathrm{P}<0.01$} \\
\hline Before oxytocin & 81.8 & 7.6 & 100 & & \\
\hline $2 \mathrm{~min}$ & 74.0 & 8.3 & 100 & & \\
\hline $4 \mathrm{~min}$ & 76.0 & 7.3 & 100 & & \\
\hline $6 \mathrm{~min}$ & 75.3 & 7.8 & 100 & & \\
\hline $10 \mathrm{~min}$ & 74.1 & 7.2 & 100 & & \\
\hline $15 \mathrm{~min}$ & 73.7 & 8.1 & 100 & & \\
\hline $20 \mathrm{~min}$ & 74.7 & 7.9 & 100 & & \\
\hline $25 \mathrm{~min}$ & 74.5 & 8.7 & 100 & & \\
\hline $30 \mathrm{~min}$ & 75.7 & 8.3 & 100 & & \\
\hline $40 \mathrm{~min}$ & 78.4 & 7.2 & 100 & & \\
\hline $50 \mathrm{~min}$ & 79.9 & 7.8 & 100 & & \\
\hline $60 \mathrm{~min}$ & 82.0 & 7.6 & 100 & & \\
\hline \multicolumn{6}{|c|}{ Table 4. Comparison of MAP at Different Interval } \\
\hline
\end{tabular}

An average decrease of $9.6 \%$ in mean arterial pressure was observed at 15 minutes after oxytocin rapid IV infusion, followed by a mean decrease of $9.3 \%$ at 2 minutes. MAP returned to baseline values after 50 minutes. $\geq 20 \%$ reduction in MAP was observed in 11 parturients at 2 minutes and 12 parturients at 25 minutes.

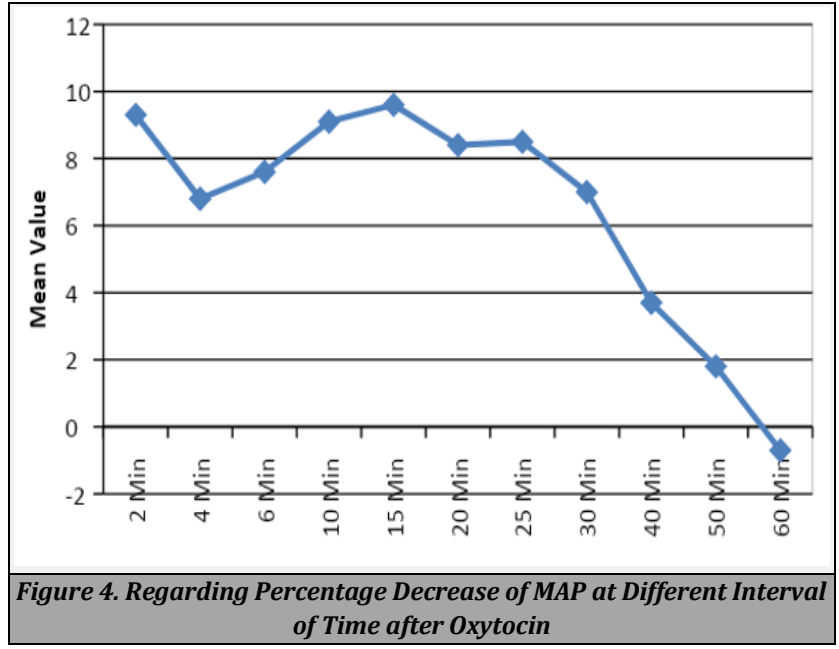

Among the hundred parturients studied, one parturient complained of chest pain during oxytocin rapid infusion, one developed atrial ectopics, and another one had ST depression. These changes reverted after 2 minutes. Generalised flushing was observed in $57 \%$ of parturients. None of them had complaints of nausea or vomiting.

\begin{tabular}{|ccc|}
\hline Adverse Effect & Count & Percent \\
ST-T wave changes & 1 & 1.0 \\
Dysrhythmias & 1 & 1.0 \\
Chest pain & 1 & 1.0 \\
Flushing & 57 & 57.0 \\
\hline Table 5. Percentage Distribution of Adverse Effects of Oxytocin \\
\hline
\end{tabular}

Most of the parturients achieved adequate uterine tone with oxytocin. Only $5 \%$ parturients required additional uterotonics. Average blood loss assessed from the mops used, drain in the suction bottle and surgical field was found to be approximately $450 \mathrm{ml}$.

\section{DISCUSSION}

Postpartum haemorrhage (PPH) is one of the leading causes of maternal mortality. The incidence of PPH is estimated to be $10 \%$ of all deliveries. ${ }^{10}$ Uterine atony accounts for most cases of postpartum haemorrhage and remains a leading cause of postpartum hysterectomy and blood transfusion. Each minute, 600 to $700 \mathrm{ml}$ of blood flows through the placental intervillous spaces; thus, obstetric haemorrhage can rapidly result in maternal shock. Uterine atony occurs more commonly after caesarean delivery than after vaginal delivery, perhaps as a reflection of the conditions that prompted the caesarean delivery or possibly because surgery disrupts the normal postpartum response to uterotonic hormones and pharmacologic agents. ${ }^{9}$ Appropriate use of uterotonics is important for the prevention and treatment of PPH.

Oxytocin is the first line of drug for prophylaxis and treatment of uterine atony after delivery of a third- trimester pregnancy. ${ }^{9}$ Oxytocin is administered by bolus and infusion to initiate and maintain adequate uterine contractility after placental delivery to minimise blood loss and prevent PPH. ${ }^{10}$

Several regimens have been used worldwide for oxytocin administration in caesarean delivery. In a prospective, randomized, multicenter study in Ireland with 2069 women who underwent elective caesarean section, all parturients received oxytocin 5 IU in one minute, followed by oxytocin 40 IU diluted in $500 \mathrm{~mL}$ saline for four hours or saline alone (placebo group).

Although the infusion of oxytocin has not affected the general occurrence of obstetrical bleeding, there was a significant reduction in the need for other uterotonic agents with the use of bolus followed by infusion of oxytocin compared with the use of oxytocin bolus alone $(12.2 \%$ vs. $18.4 \% ; \mathrm{p}<0.001$ ). Thus, the use of low dose oxytocin bolus does not spare the use of continuous infusion of oxytocin. ${ }^{12}$ We used the same bolus dose followed by maintenance dose and our need of other uterotonics was $5 \%$.

Thomas et al. studied hemodynamic effects of oxytocin 5 IU given as fast bolus or as an infusion over 5 minutes at elective caesarean section. Oxytocin bolus resulted in greater increase in heart rate ( $\Delta$ beats/ min: 17 Vs 10) and decrease in MAP ( $\Delta$ mmHg : 27 Vs 8 ). There was no difference in blood loss. ${ }^{7}$ In our study, oxytocin $5 \mathrm{U}$ bolus was given over 1 minute. Heart rate increased by 14 beats/minute and MAP decreased by $8 \mathrm{mmHg}$

In another study, 3 IU of oxytocin bolus was compared with $3 \mathrm{IU}$ of infusion over 5 minutes. Heart rate increased by $25-30$ beats/minute in bolus group and 10 beats/minute in the infusion group.

The fall in MAP in bolus group was higher. 3 patients had ST-T depression and 5 patients had chest pain in the bolus group. Both groups had comparable uterotonic effects. ${ }^{13}$ In 
our study, 1 patient complained of chest pain and 1 patient had ST-T depression.

The administration of oxytocin as a rapid intravenous bolus causes hypotension and may result in cardiovascular collapse. ${ }^{14,15}$

Patients with preeclampsia may have an unpredictable hemodynamic response to oxytocin administration (i.e., decrease in cardiac output). ${ }^{16}$ Oxytocin has a direct relaxing effect on the vascular smooth muscle, which leads to decreased systemic vascular resistance, hypotension, and tachycardia. ${ }^{17}$

Tachycardia also may result from a direct effect on specific oxytocin receptors in the myocardium and subsequently result in alterations in atrioventricular conduction and myocardial repolarization. ${ }^{17}$ Chest pain and signs suggestive of myocardial ischemia and anaphylaxis may occur. Owing to the structural similarity of oxytocin to vasopressin, water intoxication may occur and, when severe, can lead to hyponatremia, confusion, convulsions, and coma. ${ }^{9}$

In our study, we assessed the cardiovascular effects of oxytocin $5 \mathrm{U}$ given as a rapid infusion in 1 minute followed by a maintenance infusion of $10 \mathrm{U}$ in $500 \mathrm{ml}$ normal saline over 1 hour.

The maximum percentage increase in heart rate was observed at 2 minutes after oxytocin bolus which was $17.1 \%$. The heart rate values reached the baseline after 15 minutes.

Systolic BP showed a decrease in the initial 30 minutes after oxytocin bolus. The maximum percentage decrease was $5.9 \%$ at 15 minutes. Diastolic BP showed a greater fall after oxytocin bolus, which was $12.7 \%$ at 15 minutes. Diastolic BP values returned to baseline after 50 minutes.

The maximum decrease in mean arterial pressure observed was $9.6 \%$ at 15 minutes and $9.3 \%$ at 2 minutes after oxytocin rapid infusion. Mean arterial pressure returned to baseline values after 50 minutes.

Out of the hundred parturients studied one developed atrial ectopics, one had ST-T wave changes and one complained of chest pain during oxytocin bolus. These changes reverted after 2 minutes. $57 \%$ of parturients showed flushing which indicates the direct vasodilating effects of oxytocin. None of the previous studies has reported the incidence of flushing.

Uterine tone as assessed by obstetrician was found to be inadequate only in $5 \%$ of parturients. They were given inj methyl ergometrine $0.2 \mathrm{mg}$ intramuscularly.

Blood loss assessed from the drain in the suction bottle, number of mops used and from the surgical field was approximately $450 \mathrm{ml}$.

This magnitude of decrease in MAP and increase in heart rate was very well tolerated by our parturients. Hemodynamic effects of oxytocin may be more pronounced in parturients with concomitant severe blood loss or if there is unsuspected myocardial disease. No such situations were encountered in our study population. Oxytocin in the studied dose was found to be safe and effective in our parturients.

\section{CONCLUSIONS}

The oxytocin dose 5 IU rapid infusion in 1 minute followed by 10 IU maintenance infusion in 1 hour is relatively safe in parturients who are normovolemic and are having low cardiac risk. The cardiovascular effects observed were well tolerated and uterine contraction was satisfactory. The average blood loss assessed was approximately $450 \mathrm{ml}$.

Data sharing statement provided by the authors is available with the full text of this article at jemds.com.

Financial or other competing interests: None.

Disclosure forms provided by the authors are available with the full text of this article at jemds.com.

\section{REFERENCES}

[1] Dyer RA, Butwick AJ, Carvalho B. Oxytocin for labour and caesarean delivery: implications for the anaesthesiologist. Curr Opin Anaesthesiol 2011;24(3):255-61.

[2] Marcus HE, Fabian A, Lier H, et al. Survey on the use of oxytocin for caesarean section. Minerva Anestesiol 2010;76(11):890-5.

[3] Carvalho JCA, Balki M, Kingdom J, et al. Oxytocin requirements at elective cesarean delivery: a dosefinding study. Obstet Gynecol 2004;104(5 Pt 1):1005-10.

[4] Butwick AJ, Coleman L, Cohen SE, et al. Minimum effective bolus dose of oxytocin during elective caesarean delivery. Br J Anaesth 2010;104(3):338-43.

[5] Balki M, Ronayne M, Davies S, et al. Minimum oxytocin dose requirement after caesarean delivery for labour arrest. Obstet Gynecol 2006;107(1):45-50.

[6] Sarna MC, Soni AK, Gomez M, et al. Intravenous oxytocin in patient undergoing elective cesarean section. Anesth Analg 1997;84(4):753-6.

[7] Thomas JS, Koh SH, Cooper GM. Haemodynamic effects of oxytocin given as i. v. bolus or infusion on women undergoing Caesarean section. $\mathrm{Br} \quad J$ Anaesth 2007;98(1):116-9.

[8] Sartain JB, Barry JJ, Howat PW, et al. Intravenous oxytocin bolus of 2 units is superior to 5 units during elective Caesarean section. $\mathrm{Br} \mathrm{J}$ Anaesth 2008;101(6):822-6.

[9] Chestnut DH, Wong CA, Tsen LC, et al. Chestnut's obstetric anaesthesia: principles and practice. $5^{\text {th }}$ edn. Saunders 2014: p. 589, 890.

[10] Devikarani D, Harsoor SS. Are we using right dose of oxytocin? Indian J Anaesth 2010;54(5):371-3.

[11] Yamaguchi ET, Siaulys MM, Torres MA. Oxytocin in cesarean section. What's is new? Braz J Anaesthesiol 2016;66(4):402-7.

[12] Sheehan SR, Montgomery AA, Carey M, et al. Oxytocin bolus versus oxytocin bolus and infusion for control of blood loss at elective caesarean section: double blind, placebo controlled, randomised trial. BMJ 2011;343:d4661.

[13] Bhattacharya S, Ghosh S, Ray D, et al. Oxytocin administration during cesarean delivery: randomized controlled trial to compare intravenous bolus with intravenous infusion regimen. J Anaesthesiol Clin Pharmacol 2013;29(1):32-35.

[14] Bolton TJ, Randall K, Yentis SM. Effect of the confidential enquiries into maternal deaths on the use of Syntocinon at caesarean section in the UK. Anaesthesia 2003;58(3):277-9. 
[15] Langesaeter E, Rosseland LA, Stubhaug A. Hemodynamic effects of repeated doses of oxytocin during Caesarean delivery in healthy parturients. $\mathrm{Br} J$ Anaesth 2009;103(2):260-2.

[16] Langesaeter E, Rosseland LA, Stubhaug A. Hemodynamic effects of oxytocin in women with severe preeclampsia. Int J Obstet Anaesth 2011;20(1):26-9.
[17] Svanstrom MC, Biber B, Hanes M, et al. Signs of myocardial ischemia after injection of oxytocin: a randomized double-blind comparison of oxytocin and methylergometrine during Caesarean section. $\mathrm{Br} \mathrm{J}$ Anaesth 2008;100(5):683-9. 